\title{
EXTENSÃO POPULAR EM EDUCAÇÃO AMBIENTAL: convivência em comunidade de trabalho
}

\author{
Tiago Zanquêta de Soura \\ Maria Waldenez de Oliveira
}

\section{Resumo}

Este artigo é resultado de pesquisa de doutorado em Educação, que investigou a Extensão Popular em Educação Ambiental, desenvolvida por uma Comunidade de Trabalho, na cidade de Uberaba, Minas Gerais. Tem por objetivo apresentar os processos educativos inerentes a esta prática social. O referencial teórico da pesquisa está atrelado ao campo da educação popular, extensão popular e educação ambiental popular. O procedimento de coleta de dados foi a observação participante, cujos dados foram registrados em diários de campo e analisados por meio da análise de conteúdo. A extensão popular potencializou a efetivação de uma comunidade de trabalho que tem se sustentado na convivência e revelou processos educativos como o aprender a confiar, a ousar, a comunicar, a dialogar, a enfrentar o medo, a empoderar a luta, a superar a ingenuidade da consciência, com vias à construção de um conhecimento emancipatório e humanizador.

Palavras-chave: processos educativos; extensão popular; educação ambiental; prática social.

\section{POPULAR EXTENSION IN ENVIRONMENTAL EDUCATION: living in work community}

\begin{abstract}
A This article is the result of a doctoral research in Education, which investigated the Popular Extension in Environmental Education, developed by a Work Community, in the city of Uberaba, Minas Gerais/Brazil. It aims to present the educational processes inherent to this social practice. The theoretical framework of the research is linked to the field of popular education, popular extension and popular environmental education. The data collection procedure was participant observation, whose data were recorded in field diaries and analyzed through content analysis. The popular extension strengthened the effectiveness of a working community that has been sustained by living together and revealed educational processes such as learning to trust, to dare, to communicate, to dialogue, to face fear, to empower struggle, to overcome naivety awareness, with ways to build emancipatory and humanizing knowledge.
\end{abstract}

Keywords: educational processes; popular extension; environmental education; social practice.

\section{EXTENSIÓN POPULAR EN LA EDUCACIÓN AMBIENTAL:} vivir en la comunidad de trabajo

Resumen

Este artículo es el resultado de una investigación doctoral en Educación, que investigó la Extensión Popular en Educación Ambiental, desarrollada por una Comunidad de Trabajo, en la ciudad de Uberaba, Minas Gerais/Brasil. Su objetivo es presentar los procesos educativos inherentes a esta práctica social. El marco teórico de la investigación está vinculado al campo de la educación popular, la extensión popular y la educación ambiental popular. El procedimiento de recopilación de datos fue la observación participante, cuyos datos se registraron en diarios de campo y se analizaron mediante análisis de contenido. La extensión popular fortaleció la efectividad de una comunidad de trabajo que ha sido sostenida por la convivencia y reveló procesos educativos como aprender a confiar, atreverse, comunicarse, dialogar, enfrentar el miedo, 
potenciar la lucha, superar la ingenuidad. conciencia, con formas de construir conocimiento emancipatorio y humanizador.

Palabras clave: procesos educativos; extensión popular; educación ambiental; práctica social.

\section{INTRODUÇÃO}

O presente artigo resulta de pesquisa de doutorado em Educação, realizada entre 2014 e 2017, junto a um grupo de estudantes de Engenharia Ambiental de uma IES privada, na cidade de Uberaba/MG. A pesquisa teve como objetivo conhecer os processos educativos que propiciam a formação de engenheiras/os ambientais como educadoras/es ambientais, em uma prática específica de extensão popular com um grupo de moradoras/es do Bairro Vila Esperança II e Jardim Anatê, da mesma cidade. O referencial teórico da pesquisa ancorou-se na Educação Popular, Extensão Popular e Educação Ambiental Popular.

A revisão bibliográfica foi realizada por meio do levantamento de teses e dissertações no Banco Digital de Teses e Dissertações da Coordenação de Aperfeiçoamento de Pessoal de Nível Superior (CAPES) e na Biblioteca Digital Brasileira de Teses e Dissertações (BDTD), considerando-se o intervalo temporal entre 2002 e 2014, tomando os seguintes descritores: Educação Ambiental Popular; Extensão Universitária Popular; Extensão Universitária Ambiental; e Formação Engenharia Ambiental. O levantamento de artigos foi realizado nas bases Scientific Electronic Library Online (SciELO) e no Banco de periódicos da CAPES.

Com relação à pesquisa no banco de dissertações e teses da Capes, utilizando o descritor Educação ambiental Popular, foram selecionadas 3 dissertações e 2 teses. Cruzados os descritores Educação ambiental e Educação popular, foram encontradas 541 produções, das quais 5 com o Descritor Educação ambiental popular foram selecionadas. Com relação ao banco de dissertações e teses BDTD, utilizando o descritor apontado acima, foram selecionadas 2 dissertações de mestrado em Geografia, uma de Mestrado em Educação ambiental e 2 teses de Doutorado em Ecologia e Recursos Naturais. Fazendo-se a sobreposição das produções selecionadas, 2 delas foram comuns entre os bancos de teses e dissertações consultados. Quando buscados os artigos na base da Capes, a partir dos descritores Extensão popular e Extensão ambiental, foram encontrados 269 trabalhos, os mesmos encontrados utilizando apenas o descritor Extensão ambiental. Quando na busca simples, utilizando os descritores Extensão popular ou Extensão ambiental, foram encontrados os mesmos trabalhos. No mesmo modo de busca, utilizando o descritor Extensão popular ambiental, nenhum dos 27 trabalhos recuperados foram selecionados. E ainda, na mesma condição, utilizando o descritor Formação Engenharia Ambiental, foram encontrados o mesmo número de trabalhos quando pesquisado por meio da busca avançada. Vale ressaltar ainda que, na busca pelos trabalhos acadêmicos na base BDTD, foram encontrados, por meio do descritor Extensão universitária popular, trabalhos na área jurídica, de educação física, de economia solidária e de saúde, e principalmente na área de enfermagem. As produções selecionadas com o descritor Formação Engenharia Ambiental foram comuns tanto à base da Capes quanto a BDTD. As produções tratam sobre a Educação ambiental na formação de diferentes pessoas em diferentes cursos, como Administração, Direito, Economia e Enfermagem, além de versarem sobre o Ensino de Física na formação do Engenheiro Ambiental, sobre gestão de resíduos sólidos, qualidade da água, dentre outros. Na verdade, a busca por meio deste descritor revelou trabalhos que continham os descritores: "formação", "engenharia" e "ambiental" juntos ou separados, e, selecionando aqueles que apresentam os três juntos, foram encontradas apenas três produções.

Ao todo foram analisados 47 trabalhos acerca da temática da extensão (universitária popular) e da educação ambiental popular, atrelada à formação de engenheiros e engenheiras

Revista Teias v. 23 • n. 65 • jan./mar. 2022• 
ambientais. Como resultado, percebeu-se a inexistência de trabalhos que fazem essa relação. As pesquisas levantadas, em geral, afirmam que a educação popular na extensão universitária se constitui um caminho possível para a construção da prática da integralidade, sensibilizando profissionais para a produção de vínculos afetivos e políticos, dialógicos e terapêuticos, que implicam alteridade e os desafios de pensar o cuidado como valor ético e político constitutivo da humanização da vida em sociedade, pilares esses que sustentam também a pesquisa que dá origem a este artigo.

Pensam, ainda, a extensão como meio pelo qual a universidade vai cumprir sua função social, na perspectiva da formação cidadã e como espaço de seu compromisso com a sociedade na atual conjuntura, ou seja, é a extensão universitária como caminho para a construção emancipatória e transformadora das práticas educativas nas universidades, que prevê a interação entre a universidade e a comunidade na qual está inserida, a partir do potencial da temática ambiental e que sejam possíveis promotores de diálogo entre saberes.

As práticas de Educação Ambiental comunitárias ou populares estão, geralmente, muito implicadas nos processos de desenvolvimento social local, gerando maior capacidade de perceber problemas, pesar as consequências ambientais das escolhas coletivas e decidir sobre a qualidade de vida das populações (CARVALHO, 2008, p.157).

É possível perceber a relação estreita entre educação ambiental popular, a extensão e a educação popular, uma vez que suas bases fundamentais estão estruturadas no protagonismo das pessoas e dos coletivos de que participam, na conquista de sua autonomia, liberdade e emancipação.

A universidade, por meio da extensão popular, pode ser a ponte que faz a mediação entre a comunidade e seus saberes populares, com a academia e seus saberes científicos. Além disso, a educação ambiental popular atrelada à prática social da extensão popular com alunas e alunos de Engenharia Ambiental aparece como possibilidade de busca da superação da relação opressora/or/oprimida/o, por meio do diálogo dos diferentes saberes acadêmicos e populares, a fim de propor, como coloca Freire (2007), a reflexão e a ação como caminho possível para a transformação da realidade. Assim, a partir do que se apresenta, chegou-se à questão problematizadora da pesquisa: que processos educativos emergem da prática da extensão popular realizada por estudantes de Engenharia Ambiental?

O objetivo deste artigo é o de apresentar os processos educativos inerentes à prática social da extensão popular em educação ambiental desenvolvida por estudantes de Engenharia Ambiental de uma IES privada de Minas Gerais. O referencial teórico da pesquisa está atrelado ao campo da educação popular, extensão popular e educação ambiental popular e, como já afirmado anteriormente, enfoca os processos educativos que configuram parte dos resultados da pesquisa e, para tanto, foi organizado em dois momentos. No primeiro, traz a fundamentação teóricometodológica em torno do que se entende como comunidade de trabalho, diálogo e convivência, para, no segundo momento, direcionar os olhares para a compreensão dos processos educativos da comunidade de trabalho: o quem somos e a construção colaborativa do fazer extensão popular.

\section{COMUNIDADE DE TRABALHO, DIÁLOGO E CONVIVÊNCIA}

Paulo Freire (2015) propõe que a extensão universitária se configure como alternativa para a construção plural das relações entre a academia e as classes populares, uma vez que permite repensar a relação entre a construção do conhecimento e suas finalidades sociais, ou seja, pensar 
no como é produzido e a quem serve. Em outras palavras, trata-se então, de propor e pensar a extensão popular, uma vez que é "mediada por sujeitos comprometidos com as transformações sociais e implicados na conquista de uma formação universitária e uma produção de conhecimentos mais próximos aos setores populares" (ROSA, 2011, p.49). A extensão popular, conforme Cruz (2017), enquanto prática social, na perspectiva de Souza (2019), está calcada em correntes educacionais orientadas pela educação popular, de modo a interagir radicalmente com as pessoas, concretizando-se num jeito de estar no mundo, de viver as relações humanas e sociais, constituindo-se um arcabouço ético-político-social que não a coloca em concorrência com a extensão em biologia, engenharia, ecologia, cultura, artes, nem em saúde. Trata-se de uma prática identificada com a busca por um referencial humanizador, de participação democrática, justa e respeitosa, independente do espaço em que ocorra.

A comunidade de trabalho que desenvolveu tal prática social em educação ambiental, compreende tal conceito como uma visão de mundo que concebe o meio ambiente como lugar de cooperação e de parceria para realizar as mudanças desejadas no seio de sua coletividade. É importante que se aprenda a viver e a trabalhar em conjunto, em "comunidades de aprendizagem e de prática" (SAUVÉ, 2005, p.317). O meio ambiente, nessa perspectiva, é um objeto compartilhado, essencialmente complexo: somente uma abordagem colaborativa favorece uma melhor compreensão e uma intervenção mais eficaz. É preciso que se aprenda a discutir, a escutar, a argumentar, a convencer, em suma, a comunicar-se eficazmente por meio de um diálogo entre saberes de diversos tipos - científicos, de experiência, tradicionais etc. A educação ambiental concebida pela comunidade de trabalho é aquela que introduz a ideia de práxis: a ação está associada a um processo constante de reflexão crítica. A educação para a democracia, base da educação para a cidadania, torna-se essencial. Os aspectos políticos das realidades socioambientais tornam-se patentes.

Mas, para compreender a comunidade de trabalho em sua essência, parte-se do princípio de que a convivência é fundamental para sua constituição, assim como a compreendemos, de modo que consiga promover o diagnóstico das necessidades - sejam elas de ordem social, política, econômica e ambiental.

Uma comunidade de trabalho, tal como a entendemos, se constitui em torno de objetivos comuns que ultrapassam a ordem do pessoal, se situam e enraízam em compromisso com a construção de uma sociedade justa que garanta iguais direitos e tratamento diverso para diferentes condições, circunstâncias, oportunidades sócio-histórico-sociais (SILVA; ARAÚJO-OLIVERA (2004, s/p.).

A comunidade de trabalho da pesquisa é constituída pelas/os estudantes do curso de Engenharia Ambiental de uma IES privada da cidade de Uberaba/MG, em Extensão Popular, pelo doutorando e por um grupo de moradoras/es do bairro Vila Esperança II e do Jardim Anatê, que frequentam uma casa espírita na mesma cidade.

Por se tratar de uma comunidade de trabalho conformada também pela presença do pesquisador-doutorando, não se perde de vista o rigor científico e tampouco o compromisso social.

A comunidade de trabalho em que pesquisadores se formam é um lugar de intercâmbios entre diferentes culturas, onde são construídos conhecimentos com o apoio de referências teórico-metodológicas que contemplam, reconhecem e respeitam a diversidade da sociedade e com ela aprendem [..]. Em tal comunidade, a multiculturalidade, pois, mais do que discurso, é vivência (SILVA; ARAUJO-OLIVERA, 2004, s/p.). 
Em comunidade de trabalho os diferentes conhecimentos são colocados em diálogo, sem hierarquias.

A comunidade de trabalho tem uma amplitude que permite transitar do espaço acadêmico à sociedade e desta àquele, reconhecidos cada um deles como legítimo em suas diferenças, especificidades, funções. [...]. Contém, ela, a visão de mundo que cada um de seus participantes herdou das comunidades de origem, presente em maneira própria de apreender realidades, aprender e interpretar informações, formular pontos de vista, julgamentos, de mirar situações, fatos, acontecimentos. Trata-se de pontos de vista quase nunca expressos, pois dificilmente são aceitos pela academia (SILVA; ARAUJO-OLIVERA, 2004, s/p.).

A constituição de uma comunidade de trabalho requer o uso da sensibilidade, da exploração das sensações, do diálogo entre os diversos saberes, do popular e científico, numa constante interação que denominaremos de convivência metodológica

Convivência é palavra-chave para ao diálogo. É tão vital na perspectiva de pesquisa entendida por nós que deve ser introduzida e explicitada na metodologia do trabalho. Deste modo, passa a ser não apenas um dado da existência de quem faz a pesquisa, do(a) pesquisador(a), mas sim, o cerne do "fazer", explicitado, experimentado, avaliado. A convivência dialógica não se configura como uma etapa do processo de pesquisa e, sim, como o próprio processo da pesquisa. Nela constrói-se confiança, valorizando as trocas de experiências de mundo, compartilhando saberes, fundando o respeito mútuo, permitindo relações sociais autênticas, de modo que os sujeitos envolvidos na pesquisa troquem experiências de vida e visões de mundo, no olho-no-olho, abrindo caminhos para a construção de um processo que seja libertador, humanizador (OLIVEIRA; RIBEIRO JUNIOR; SILVA; SOUSA; VASCONCELOS, 2014, p.133-134).

Convivência é aqui utilizada no sentido de viver com, algo mais do que estar perto ou junto, é estabelecer uma sintonia de sentimentos que nos permite agir em prol do bem comum, ou seja, da vocação ontológica para o ser-mais, como coloca Paulo Freire (2008), mesmo sabendo que, conforme coloca Petronilha Silva (1987), existam conflitos. A convivência é entendida como possibilidade, e não como certeza, uma vez que é parte do processo de humanização. Aproximarse é um primeiro passo para a convivência, é tornar-se próximo das pessoas, ou seja, é conhecê-las e conviver com elas, conforme coloca Leonardo Boff (2006). Por isso, é interessante

[...] destacar esta característica da palavra aproximar também no sentido [...] de proceder a uma leitura de mundo, junto com as pessoas que nele estão imersas. O processo de aproximação, portanto, celebra o encontro de sujeitos que passam a construir juntos, uma vez que convivem no mesmo espaço e que estão dispostos a dialogar sobre suas visões de mundo. [...] $\mathrm{Na}$ aproximação, o(a) pesquisador(a) vai apreendendo aspectos importantes para condução das conversas e entrevistas, tais como por onde pode começar, o que incomoda ou o que impede o prosseguimento da investigação, bem como o que é preciso fazer para superar as dificuldades. [...] é um momento muito importante de um processo que se pretende ser realizado de forma dialógica, coletiva, participativa, colaborativa (OLIVEIRA; RIBEIRO JUNIOR; SILVA; SOUSA; VASCONCELOS (2014, p.127). 
A aproximação entre o pesquisador-doutorando, o grupo de estudantes e o grupo de moradores frequentadoras/es da casa espírita para conviver, pressupunha que, para tanto, seria necessário a construção cotidiana do diálogo como elemento constituinte das relações, alimentando a fé, o amor, a confiança e a esperança, no sentido proposto por Freire (2008), com a finalidade de valorizarmo-nos enquanto sujeitos históricos, na construção de um conhecimento crítico da realidade. A partir do momento que os grupos que compõem a comunidade de trabalho passaram a se conhecer melhor, surgiram laços de amizade, de fraternidade, de amorosidade e de confiança, elementos que puderam ser construídos e fortalecidos pela convivência em diálogo.

Por meio do diálogo, na perspectiva de Paulo Freire (2008), o grupo extensionista, do qual o pesquisador já fazia parte, pode dizer a sua palavra, inclusive compartilhar seus anseios sobre como seria desenvolver a extensão. Da mesma forma como as/os moradoras/es disseram a sua palavra, quando também apresentaram suas expectativas junto às/aos estudantes extensionistas, com o objetivo de construir soluções para os problemas que foram, paulatinamente, revelados.

Constituir uma comunidade de trabalho é compartilhar do entendimento de que os saberes que a circundam têm diversas raízes, sejam populares, sejam acadêmico-científicas, religiosas, entre outras. Destacamos, por isso, que existe a busca pela convivência na diversidade, entre os saberes, com a finalidade de não os hierarquizar, pois como afirma Paulo Freire (2005, p.68), "não há saber mais, nem saber menos, há saberes diferentes", que se complementam. Entendemos também que esses saberes estão vinculados ao saber de experiência feito, na perspectiva de Larrosa-Bondía (2002), uma vez que para o autor, a experiência não é o que acontece, mas o que nos acontece, o que nos passa, o que exige parar para pensar, parar para olhar, parar para escutar, pensar mais devagar, olhar mais devagar e escutar mais devagar.

As experiências vividas são particulares, subjetivas, relativas ao contexto vivido, pessoal, o que, segundo Victor Valla (1996), carece de cuidado no momento da interpretação, pois a formação de cada uma/um, a sua história de vida e as suas vivências cotidianas condicionam uma determinada leitura de mundo e do outro com o qual me disponho a conviver. Falando especificamente a comunidade acadêmica e a gestores de serviços públicos de saúde, o autor ressalta o necessário cuidado com a interpretação da fala do outro, com o objetivo de evitar julgamentos apressados, uma vez que o que se apresenta como "falta de iniciativa e/ou apatia é, para a população, uma avaliação (conjuntural e material) rigorosa dos limites de sua melhoria" (p.181). Caso contrário, uma interpretação pode levar a "uma suposta identidade, consciência de classe e organização, que, na realidade, é uma fantasia nossa" (MARTINS, 1989, apud VALLA, 1996, p.182).

Teixeira; Ribeiro Junior; Souza; Oliveira; Costa; Souza; Almeida; Bogado; Sousa; Fidélix; Souza (2015), citando Xesús Jares (2008), colocam que a convivência pressupõe a construção de valores, de sistematização de experiências, de modos de organização, de maneiras de pensar, relacionar e agir, de metodologias para enfrentar conflitos, de compreensões linguísticas, de modos de expressar os sentimentos, expectativas sociais e educativas, de cuidado, etc. Por meio do diálogo, busca-se a compreensão de outras culturas e o estabelecimento de acordos para que seja possível a construção da unidade na diversidade.

É a partir do uso da sensibilidade, da exploração das sensações, do diálogo entre os diversos saberes, do popular e científico, especialmente, como sustenta a Extensão Popular, numa constante interação, é que se deu a pesquisa. Ou seja, por meio da convivência foi possível aprendermos

não apenas os saberes do mundo natural, mas a complexa teia de símbolos, de sentidos e de significados que constituem o mundo da cultura. Quase tudo o que nós vivemos em nossas relações com outras pessoas ou mesmo com o nosso mundo, como no próprio contato direto com a natureza, pode ser, também, um

Revista Teias v. 23 • n. 65 • jan./mar. 2022• 
momento de aprendizado. Podemos estar ou não conscientes disto, mas cada troca de palavras, cada troca de gestos, cada reciprocidade de saberes e de serviços com uma outra pessoa, costuma ser também um momento de aprendizagem. De uma para a outra, as pessoas que se encontram, conversam, dialogam, deixam passar de si mesmos à outra algo de suas palavras, de suas idéias, de seus saberes, de suas sensibilidades. Querendo ou não (mas é melhor estar querendo) estamos, no conviver com outros e com o mundo, nos ensinando e aprendendo (BRANDÃO, 2005, p.86).

A comunidade de trabalho constituiu um espaço de ação, pesquisa, exposição de práticas, dinâmicas e vivências que possibilitaram a construção coletiva do conhecimento no interior e por meio da cultura, o que permitiu o aprendizado em "reciprocidade de consciências", conforme Fiori, citado por Freire (2005, p. 6). É preciso pensar a cultura como

um ato da vida humana: é produção-consumidora e consumo-produtivo. Os objetos ou símbolos de cultura se dão tais no próprio ato de está-los "usando" ou "criando", no momento de estarem integrados ao ato do trabalho. Até a festa ou a recriação cultural, e por isso a arte, é incompreensível sem a referência, em última instância, ao ato do trabalho cotidiano: do camponês no campo, do operário na fábrica, dos responsáveis pelo lar em casa etc. (DUSSEL,1997, p.193).

A partir dessas compreensões teóricas, foi possível discutir e elucidar alguns dos processos educativos inerentes à prática social experimentada pelo grupo de estudantes extensionistas junto à comunidade de trabalho, possibilitados pela convivência e diálogo. Antes, porém, traremos alguns apontamentos acerca dos procedimentos utilizados no trabalho de campo.

\section{A OBSERVAÇÃO PARTICIPANTE E ANÁLISE DE CONTEÚDO}

Optou-se pela modalidade de pesquisa com cunho qualitativo (FLICK, 2009), finalidade descritiva (VERGARA, 2009), utilizando-se da pesquisa de campo (VERGARA, 2009), por meio da observação participante, pois permite registrar os eventos assim que ocorrem, além de permitir a comparação entre as informações recebidas das pessoas e a própria realidade, conforme apontam Marina de Andrade Marconi e Eva Maria Lakatos (2002). A pesquisa de campo se deu por meio da realização de dezessete encontros previamente marcados, utilizando rodas de conversa. O registro das observações foi feito em diários de campo que entendemos como o "relato escrito daquilo que o investigador ouve, vê, experencia e pensa no decurso da recolha e refletindo sobre os dados de um estudo qualitativo", a partir do que colocam Roberto Bogdan e Sari Biklen (1994, p.150). Os registros foram posteriormente organizados e digitados, a fim de permitir a leitura geral do material coletado. Além do registro escrito também foram feitos registros gravados.

A organização dos dados deu-se da seguinte maneira: a) escuta das gravações: escuta atenta das gravações em sua íntegra, com o objetivo de enriquecer e aprimorar ainda mais os registros no caderno de campo; b) transcrição das gravações: transcrição dos momentos de diálogo necessários para complementar os registros das falas que já constavam nos diários de campo, mas que não estavam feitos em sua integralidade; c) revisão dos diários de campo: leitura geral dos registros no caderno de campo, com vistas a relembrar todo o processo da pesquisa e, a partir disso, atrelá-los às gravações; d) reestruturação dos diários de campo: a partir da revisão dos registros e das transcrições, organizamos os diários de campo, inserindo parte dos diálogos transcritos em 
consórcio com os registros realizados. Entendemos que esse processo permitiu que os diários ganhassem ainda mais detalhamento. Cabe destacar que os nomes dos/as participantes citados no texto são pseudônimos, como forma de garantir o anonimato, mediante autorização registrada no Termo de Consentimento Livre e Esclarecido, por ocasião da realização do trabalho doutoramento que dá origem a este artigo. Esta pesquisa foi chancelada pelo Comitê de Ética em Pesquisa da instituição de vínculo dos pesquisadores autores deste trabalho.

Para análise dos dados, utilizou-se da análise de conteúdo, conforme propõe Laurence Bardin (2006), que propõe quatro fases como componentes do processo de análise de conteúdo: pré-análise, codificação, categorização, análise e interpretação.

Num primeiro momento, na pré-análise, os documentos analisados foram os diários de campo. A transformação dos dados em unidades de registro deu-se a partir da convergência interpretativa dos parágrafos dos diários de campo. Cada parágrafo dos diários de campo, especialmente aqueles provenientes das transcrições dos diálogos estabelecidos e organizados nos diários, foi tomado como unidade de registro. A partir da convergência entre essas unidades, foram elaboradas as categorias iniciais, intermediárias e finais. Neste trabalho, apresenta-se os resultados em torno da categoria "quem somos e a construção colaborativa, na comunidade de trabalho", frutos do fazer extensão popular em educação ambiental.

\section{O QUEM SOMOS E A CONSTRUÇÃO COLABORATIVA DO FAZER EXTENSÃO POPULAR}

Discute-se o quem somos a partir da compreensão do grupo extensionista e da constituição da comunidade de trabalho, com a finalidade de compreender melhor os traços identitários e os processos educativos que emergiram desse contexto, ressaltando a importância da organização da comunidade de trabalho e a importância da escuta.

O grupo extensionista, durante os encontros realizados, refletia constantemente a prática a que estavam mergulhados, na perspectiva de compreendê-la criticamente e encontrar caminhos salutares para a consolidação dos objetivos traçados. Havia um esforço constante para não perder de vista a condição do fazer coletivo, do exercício do respeito e da escuta, da valorização dos saberes, quer fossem aqueles que elas/eles possuíam, quer aqueles que as pessoas com as quais estavam fazendo extensão, também possuíam, em diálogo como proposto por Freire (2008, 2011a) e com a busca por uma convivência pautada na solidariedade e na confiança, como propõe Silva (1987).

João (2017), em um dos diálogos com o grupo, fez o seguinte comentário:

Esse jeito que a gente escolheu para fazer isso [extensão] é o mais difícil. Escutar
as pessoas e transformar os desejos em desejos comuns, não é fácil. Você vê só
o trabalho que é elaborar um ofício simples, que foi pensado junto. Seria muito
mais fácil se a gente fosse escrever com as nossas próprias ideias. Mas a gente
está fazendo com eles, então é diferente, tem mais peso, num tem? Pode ser que
não muda a realidade de imediato, mas a gente pelo menos está se esforçando,
cada um fazendo a sua parte, para mudar, né?! [...] Então... se a gente acredita
nisso, que a gente pode usar o conhecimento que a gente conseguiu aqui e levar,
mas num é só levar, é usar ele e construir outro, a gente está atingindo nossos
objetivos (JOÃO, 2017).

Para o grupo extensionista, existia o desafio da prática da escuta como caminho e possibilidade para a construção coletiva. Essa é uma premissa da educação popular, da educação

Revista Teias v. 23 • n. 65 • jan./mar. $2022 \bullet$ 
ambiental popular e da própria extensão popular: escutar com o intuito de compreender, a fim de evitar o equívoco da interpretação, como aponta Valla (1996), e compreender a realidade a fim de transformá-la. Mas essa transformação tem suas raízes na percepção crítica da realidade vivida, percebida e compreendida por aquelas e aqueles que dela fazem parte. Não quer dizer também que a intenção de "fazer junto", de "fazer com" por si, já implica em dialogicidade", ou ainda, em comunicação que permita compreensão mútua. Essa dialogicidade só se confirma e se consolida na experiência vivida, da convivência, que, como afirmado anteriormente, também pode incorrer em conflitos. Sobre o diálogo entre conhecimentos, João (2017), afirma que se "pode usar o conhecimento que a gente conseguiu aqui e levar, mas num é só levar, é usar ele e construir outro". Ou seja, que se propõe a construir um outro conhecimento com as pessoas, a partir da extensão que descobriram fazer. De acordo com Freire (2005) respeitar os saberes das pessoas, gerados em sua prática social - nas trocas conectivas entre as intersubjetividades das mulheres e homens, não significa a idealização do saber popular, mas, precisamente, da percepção exigida pelo "pensar certo" e de que não há estado absoluto de ignorância ou de saber, uma vez que todas as pessoas sabem alguma coisa do mesmo modo que ninguém ignora ou domina todo o saber.

Paulo Freire $(2005,2008,2011$ a) afirma que as diferentes formas que, ao longo dos tempos e dos espaços, as relações entre as pessoas vão assumindo, configuram o desafio das possíveis formas de convivência, que podem nos humanizar ou desumanizar, na economia, na política e no saber, em diferentes períodos históricos e contextos geográficos. Entendemos que a convivência num mesmo espaço de diferentes culturas não é algo dado, natural e espontâneo. Trata-se de uma produção histórica que implica decisão, vontade política, mobilização, organização de cada grupo cultural com vistas a fins comuns e, por isso, demanda uma prática que seja coerente com esses objetivos e uma ética fundada no respeito às diferenças.

A fala de Mônica (2017), que segue, emitida no processo de construção da convivência, revela um processo de aproximação entre o grupo extensionista e o grupo de populares, que foi marcado por ansiedade, medo, ousadia, dúvidas, incertezas.

Eu lembro quando a gente começou, tudo cruzinha, com o maior frio na barriga, que a gente sente até hoje, meio sem saber como fazer, que jeito fazer. Lembro que a gente vestiu a camisa e foi. A gente precisa acreditar que podemos fazer. Âs vezes é complicado, tem conflitos também, tem desinteresses, mas isso é normal. Se a gente tem boa vontade, a gente consegue sim. [...]. A gente aprende a ver a realidade com outros olhos. A gente até sente a mesma raiva que as pessoas sentem das situações que elas narram que vivem. [...]. Mas, muitas vezes, não conseguem enxergar os caminhos para tentar resolver. É mais fácil alguém, às vezes, de fora, olhar e sugerir. Não impor né? (MÔNICA, 2017).

Segundo Freire (2007) a ansiedade, o nervosismo e a insegurança constituem o medo que resulta em alienação, que entorpece diante do vindouro. Um medo de arriscar-se à aventura de criar. Um medo que incita a formalidade, limitando a vontade de transformar, de lutar pela liberdade. No caso do grupo extensionista, no lugar deste risco que paralisa, nasceu a coragem do compromisso, ligada à esperança. Dessa forma, surgiu a ousadia, intimamente ligada à coragem de arriscar, de passar pela experiência.

\footnotetext{
${ }^{1}$ O diálogo, segundo Paulo Freire (2005) possibilita a escuta e a compreensão do outro, além de viabilizar experiências de solidariedade, de respeito ao outro e às diferenças, assumindo, por isso, uma dimensão ética. "A dialogicidade verdadeira, em que os sujeitos dialógicos aprendem e crescem na diferença, sobretudo, no respeito a ela, é a forma de estar sendo coerentemente exigida por seres que, inacabados, assumindo-se como tais, se tornam radicalmente éticos" (FREIRE, 2005, p. 60).
} 
A aproximação é o primeiro passo para a convivência, que para nós tem o sentido de viver com, buscando sintonia que permita a busca pelo bem comum a todas e todos, fortalecendo, como afirma Freire (2008) a vocação ontológica para o ser-mais, embora conforme coloca a professora Petronilha Silva (1987), exista conflitos. Dessa forma, a convivência é também possibilidade para a humanização. A comunidade de trabalho pautou-se na tentativa da construção coletiva, num esforço constante para a humanização, para a vocação ontológica do ser humano em ser mais.

De acordo com Paulo Freire (2005) é com inteireza que nós operamos o mundo enquanto presenças imaginativas, críticas ou ingênuas, e, por isso, a hominização não é adaptação, mas inserção consciente, transformadora, um processo sócio-histórico-cultural de humanização do mundo, que deve estar pautada no diálogo entre conhecimentos, na escuta, assim como aconteceu na comunidade de trabalho. $O$ recorte que segue ajuda na compreensão:

Problemas todo mundo tem, mas é difícil achar alguém para arregaçar as mangas e ajudar a resolver o problema. [...]. Quem sabe não conseguimos alguma coisa? Então, vejo que a gente tem muita coisa a fazer aqui. Primeiro, sinto que a gente precisa escutar deles o que eles precisam mesmo. Para só depois a gente sentar, pensar, propor para eles e ver com eles se o que pensamos está bom, ou se, talvez, a gente não possa sentar com eles e pensar com eles o que fazer ao invés de a gente propor. Como já disse, eles sabem das necessidades deles. A gente pode colaborar. Vamos colaborar como pudermos (SARA, 2017).

Podemos compreender também, a partir desse contexto, que conforme afirma Freire (2005) o ser humano é subjetividade ética em comunhão, diálogo um com o outro, capaz de amar um ao outro, e a partir desse amor, lutar por justiça que representa o ápice da consciência ética. Para o autor, o outro é lugar desde onde é possível se começar, pela via do diálogo amoroso, um processo de humanização, que liberta e reconhece a dignidade humana. Para que a comunidade de trabalho se constituísse como tal, o reconhecimento da alteridade foi crucial. Nessa perspectiva, o diálogo é comunhão, acolhimento, encontro amoroso, de pessoas que buscam a transformação. Vejamos as implicações do diálogo, a partir do recorte que segue.

É difícil a gente conseguir falar com eles né, porque a gente fica meio sem jeito de saber puxar um assunto. Mas é só a gente escutar né, aí se precisar, a gente fala, se souber o que falar né. [...] é complicado mesmo, a gente fica nervoso, mas vamos conversar sobre as coisas da vida, do cotidiano, de coisas que todos e todas falamos diariamente. Aí, pouco a pouco, a gente vai conversando e o assunto vai surgindo. Entende? Mas eu não acho fácil abordar as pessoas assim, até porque a gente não conhece, elas não nos conhecem. Mas não podemos ter receio (JOÃO, 2017).

O receio para o diálogo implica o respeito à pessoa em sua condição individual, que pode ser o melhor caminho para a humanização, pois, como afirma Freire (1996, p.46) "a assunção de nós mesmos não significa a exclusão dos outros. É a outredade do não-eu, ou do tu, que me faz assumir a radicalidade do meu eu". O que a comunidade de trabalho busca, é a luta por mais solidariedade social e política, pelo seu reconhecimento.

Estávamos organizados como uma unidade composta a partir da diversidade, das várias subjetividades, lutando por uma causa comum. Em outra circunstância, ouvimos um comentário de Mônica (2017):

Como é interessante né?! Não é preconceito, longe de mim isso, mas quem olha para a simplicidade daquelas pessoas não imagina como elas são inteligentes, né?! 
Não me levem a mal, eu não quero ser mal interpretada. Mas é que é muito fácil a gente julgar pela capa, enquanto a realidade pode ser bem diferente (MÔNICA, 2017).

Victor Valla (1996) já nos alertava quanto à crise de interpretação, que também pode ter por contexto o que está registrado no recorte acima. Embora Mônica (2017) se justificasse por aquela percepção, vai deixar clara a expressão de sua surpresa em relação às pessoas que viviam aquela realidade. Isso mais uma vez vai reforçar que o projeto do opressor está introjetado nas pessoas, e essa fala vai refletir o posicionamento hierárquico que muitas vezes ocupados, dificultando-nos uma análise crítica da realidade desenraizada do lugar onde temos enraizadas as nossas experiências. Integrar a comunidade de trabalho não significa, por isso, fazer parte constante daquela realidade, mas, em estando nela, poder pensar a partir dela, superando a ingenuidade para assumir o posicionamento crítico, como nos ensina Freire (2011b).

Ainda acerca da constituição da comunidade de trabalho, trazemos a fala de Lúcia (2017), que vai refletir a convivência em diálogo sob outra perspectiva, que nos ajuda ainda mais dizer quem somos e o que fazemos, enquanto unidade formada a partir da diversidade.

Acho que eu consigo resumir bem isso. A gente tem conversado e percebido que com a chegada de vocês, e com a permanência, porque a gente entende que chegar, ficar um ou dois dias não ia dar em nada. É muito mais interessante porque vocês ficaram, estão com a gente, e a convivência só se deu por causa disso. A gente aqui fala e resolve os problemas e coisas da vida, juntas, todas as pessoas comentam, falam, sem medo, acreditando que nós podemos realizar. É muito legal porque a gente até esquece que vocês vêm da faculdade, da universidade né? É difícil ver isso por aqui, porque ninguém gosta de misturar com a pobreza, e ainda mais para fazer as coisas com a gente. Tá cheio de gente que já veio aqui resolver para nós, mas não com a gente (nesse momento ela foi aplaudida, e estava bastante emocionada) (LÚCIA, 2017).

Pois é, para nós que estávamos na faculdade é um aprendizado diferente, porque essa convivência falta para a gente enxergar melhor os problemas ambientais, ou de outras origens, para lutar para resolver. A técnica é importante, mas estar junto é mais importante ainda. Fazer um projeto e executar às vezes é até fácil, o difícil é atender as expectativas de quem se beneficiará ou não com ele. Aqui estamos aprendendo que escutar e pensar junto é o melhor caminho para chegar ao objetivo comum (JOÃO, 2017).

A fala de Lúcia (2017), quando traz: "A gente tem conversado e percebido que com a chegada de vocês, e com a permanência, porque a gente entende que chegar, ficar um ou dois dias não ia dar em nada" levam-nos à compreensão de que, conforme apontam Maria Waldenez de Oliveira e Eduardo Navarro Stotz (2004), ir à campo com a finalidade de conseguir os dados necessários à pesquisa, não é conviver, mas tão somente visitar. Colocam, por isso, que "o convívio pode trazer aos que nele se encontram uma visão mais clara do outro, pois é nesse convívio que as pessoas se posicionam politicamente" (OLIVEIRA; STOTZ, 2004, p.12). Desse modo, uma conversa pode ser uma rápida visita, bem como o caminho para o convívio, pressupondo a convivência metodológica, "não apenas como dado mas, enquanto metodologia pode ser extremamente rico. Nele, as pessoas se colocam abertamente e o conhecimento é mais autêntico" (OLIVEIRA; STOTZ, 2004, p. 12-13).

Conviver é conhecer a vida humana sempre em movimento: ora suave, ora abrupto; ora lento, ora vertiginoso; ora leve, ora sufocante; ora harmonioso, ora 
ensurdecedor. Vidas, vivências, amizades, sabores, cheiros, texturas, sons, palavras, cores, lágrimas e sorrisos tecem uma rede que embala o pesquisador(a), $\mathrm{O}$ (a) profissional, integrando-o(a) aos movimentos do viver e redirecionando-lhe o olhar para novas perspectivas, visões do mundo (OLIVEIRA, 2009, p. 318).

Tomando outro trecho da fala de Lúcia (2017): "É muito mais interessante porque vocês ficaram, estão com a gente, e a convivência só se deu por causa disso" suscita a discussão em torno da importância de que "para ter a vivência da e na comunidade, não sendo da comunidade, [...], é necessário penetrar na comunidade, pesquisar, estar lá pessoalmente. Não basta [...] mandar alguém pesquisar" (OLIVEIRA; STOTZ, 2004, p. 13). Ou seja, esta fala nos alerta que conviver, dialogar, estar juntos, reunidos, pode abrir caminhos para a construção de laços de confiança, fraternidade, possibilitando à comunidade de trabalho a busca por soluções dos problemas daquela comunidade. Tanto que, pode ser que nem todos/a, que a integram, tenham a compreensão desse interesse. Por isso, "estando perto, somente assim, [...], é possível "pesquisar o olhar" do outro, conhecê-lo" (OLIVEIRA; STOTZ, 2004, p. 13), assim como afirmava Lúcia (2017) "vim gente aqui e olhar para nós e falar que vai fazer para nós é uma coisa. Agora fazer igual vocês fizeram, é bem diferente".

A convivência entendida a partir dessa fala é aquela que só é possível a partir da chegada e da permanência das pessoas, passando a estar juntas e juntos, em amplo espaço de dialogicidade, de escuta, de partilha de experiências, mas mais que isso, na crença de realizar, de agir para a mudança, para a solução de problemas. Essa permanência de quem chega permite que a diversidade se torne unidade, como se pode perceber na fala de Lúcia (2017), quando afirma que "a gente até esquece que vocês vêm da faculdade, da universidade". Ou seja, permite que a mistura aconteça, uma vez que, na fala dela, percebe-se ainda o reforço dos estereótipos que carregam as classes subalternas, socioeconomicamente periféricas, marginalizadas, e que por isso, está dentro da comunidade de trabalho.

João (2017), posteriormente à fala de Lúcia (2017), traz que o conhecimento aprendido na universidade, especialmente os técnicos, não são suficientes para resolver os problemas, sejam eles ambientais ou de outra natureza, sejam resolvidos, atribuindo a convivência, especialmente naquela comunidade de trabalho, um caminho possível para chegar ao êxito dos anseios que se tornaram comuns. Essa mobilização, tão presente nessa comunidade de trabalho é, de acordo com Paulo Freire (2007) uma atitude que tem um intenso sentido político, contendo em si os valores que a conduzem. Freire (2005) afirma que a mobilização implica luta com as pessoas e não por elas, nem para elas, numa atitude que supera o espontaneísmo e o voluntarismo.

De acordo com Freire (2007), quando a mobilização é simultaneamente objetivo e condição para o processo de libertação, torna-se uma atividade político-pedagógica, que ocorre por meio das pessoas, mas especialmente, por meio dos processos nos quais as pessoas se colocam e se afirmam como pessoas, senti-pensantes, protagonistas.

Eu ficava inconformada, porque eu acredito que a gente tem que fazer junto, tudo no seu tempo, que pode demorar ou não, mas a gente tem que respeitar o limite e os interesses das pessoas, em coletivo. Produzir um movimento em defesa dos interesses de todos e todas. Se for para predominar o meu interesse só, para que eu vou lá fazer extensão? (MÔNICA, 2017).

O recorte acima leva-nos ao entendimento de que a mobilização e a organização popular experenciada pela comunidade de trabalho se dá por meio de participação ativa, e os estudantes compreendiam isso e planejavam como realizá-la. De acordo com Freire (2005) exige também 
conscientização, organização e convivência, pois quanto maior for o respeito às iniciativas das pessoas interessadas e a troca de ideias com elas, maior a eficácia da mobilização.

A conscientização, segundo Freire (2005) é condição para a assunção do comprometimento de mulheres e homens diante do contexto histórico-social em que vivem. No processo de produção do conhecimento, as pessoas tendem a se comprometer com a realidade, sendo esta uma possibilidade que está intimamente associada a práxis humana, tanto que por meio da conscientização é que as pessoas assumem seu compromisso histórico no processo de fazer e refazer o mundo, dentro de possibilidades reais, concretas, palpáveis, fazendo e refazendo também a si mesmos. Para o autor, conscientização não é apenas "tomar consciência", visto que "a tomada de consciência não é ainda a conscientização, porque esta consiste no desenvolvimento crítico da tomada de consciência" (FREIRE, 2005, p.26). A fala Mônica (2017), permite-nos compreender que na comunidade de trabalho reside a busca para a construção de um outro conhecimento a partir da consolidação do respeito, dos acordos, do diálogo que educa, que escuta e compreende, permitindo a partir da práxis, a tomada de consciência.

Trazemos aqui parte dos registros de um diário de campo que apresenta um diálogo reflexivo quanto ao trabalho desenvolvido junto à comunidade de trabalho, especialmente no que diz respeito à construção compartilhada e ao planejamento participativo.

Eu estou entendendo que tudo o que é feito aqui é feito junto. Ninguém decide nada sozinho, tudo é feito quando as pessoas concordam, se não concordam a gente muda o rumo. Nós somos um grupo, não é? Uma comunidade igual a gente escuta que é. Se a gente faz junto, se a gente pensa junto, se a gente decide junto, se a gente observa as coisas da nossa vida juntos. (PEDRO, 2017).

É meus filhos, a gente sempre tem procurado o caminho da boa conversa, para decidir com sabedoria, porque o povo daqui sabe muito, sabe muito da dor que passa, dos problemas que tem. Só para chegar aqui é aquele sacrifício de todo santo dia, e a gente tá aí na luta. Vocês da universidade e nós daqui do bairro, desse centro abençoado, juntando num grupo só. Vocês não moram aqui, mas é como se fosse tudo daqui. Acho que é isso mesmo (EDUARDA, 2017).

É possível compreender, à luz do que coloca Oliveira (2009), que quando se busca a realização de trabalhos coletivos, em comunhão, em diálogo, é preciso estreitar o compromisso ético e social com o ponto de partida e de chegada, aprendendo a conviver e, com esse aprendizado, gostar de si e da vida. Trata-se de um aprendizado pessoal e profissional, que permite a ampliação do saber de experiência feito e o aprofundamento do conhecimento construído. No caso da comunidade de trabalho, como se percebe na fala de Pedro (2017) e Eduarda (2017), havia a tentativa de enfrentar o distanciamento entre a ciência e a sociedade, abrindo espaços para que as pessoas pudessem contribuir um conhecimento por meio do cruzamento complementar entre os saberes populares e científicos, superando o caráter reducionista vigente, especialmente quanto ao papel desempenhado pela extensão.

Esses registros feitos em diferentes momentos, fecham a discussão em torno da "comunidade de trabalho em diálogo". Como afirma Freire (2005), o lugar onde vivemos é uma construção humana, por isso, recriar esse espaço dentro das condições historicamente favoráveis é tarefa que requer ousadia cotidiana, de todas as pessoas. Existe um engajamento, um comprometimento das pessoas em torno de quefazeres articulados, na direção de uma vida mais digna e bonita para todas e todos. 


\section{CONSIDERAÇÕES FINAIS}

Foi a partir da convivência que os/as integrantes da comunidade de trabalho descobriram que faziam extensão popular e foram, por isso, em busca dessa compreensão. Compreende-se que não há um saber mais ou saber menos, mas sim saberes que se complementam e, por isso, se deu a construção de um caminho que permitiu, coletivamente, a elaboração de reflexões que pudessem colaborar com a transformação da realidade que se fazia opressora e excludente.

Este trabalho, a partir da extensão popular como via de legitimação do papel e da função social da universidade, colabora para que se possa buscar por condições dignas de vida, alimentando a possibilidade de afirmação de identidades, o que constitui uma das marcas da participação das classes populares nos movimentos da cotidianidade vivente. Ao mesmo tempo, mostra também que ainda há um longo caminho a ser percorrido, de luta e resistência contra a exclusão social, contra a potencialização da desigualdade, da exploração do trabalho humano e do consumismo constantemente estimulado. A extensão popular é um caminho possível para essa superação, de modo que não se promova uma instrução para as pessoas, mas a construção de conhecimentos com elas, além de garantir a sustentação da função social da universidade.

A prática social da extensão popular potencializou a efetivação de uma comunidade de trabalho que tem se sustentado na convivência, por meio de processos educativos dialógicos, direcionados ao exercício da alteridade, da autonomia, do enfrentamento do medo, do estabelecimento da confiança e da amorosidade.

Compreende-se que a insegurança e as muitas incertezas que permearam vários dos encontros da comunidade de trabalho, foram frutos da relação que estava se estabelecendo. $O$ "como será que vai ser?" foi atravessado pela confiança construída na convivência e de um processo de dialogicidade pautado na escuta e na proposição partilhada, discutida, debatida e compreendida, senão por todos, pela maioria das pessoas que constituíam a comunidade de trabalho. Trata-se de um processo lento, que não está dado, mas sim, é construído, alimentado e vivido, promovendo o diálogo entre subjetividades, o que permitiu a escolha de um caminho consensual para o enfrentamento das dificuldades conferidas pela realidade que se apresentava.

O fazer extensão, por isso, ampliou-se na medida em que a comunidade de trabalho se constituiu, uma vez que se entende que todas e todos são protagonistas no processo de construção do conhecimento e, que todas e todos, na perspectiva de Freire (2008), naquela comunidade de trabalho, de modo especial, estavam em busca do "ser mais".

\section{REFERÊNCIAS}

BARDIN, Laurence. Análise de conteúdo. Tradução de Luís Antero Reta e Augusto Pinheiro. Lisboa: Edições 70, 2006. (Obra original publicada em 1977).

BOFF, Leonardo. Virtudes para um outro mundo possivel, volume II: convivência, respeito, tolerância. Petrópolis, Vozes, 2006.

BOGDAN, Roberto; BIKLEN, Sari. Notas de Campo. In: BOGDAN, Roberto; BIKLEN, Sari. Investigação qualitativa em educação: uma introdução à teoria e aos métodos. Porto Alegre: Porto Editora, 1994, p.150-175.

BRANDÃO, Carlos Rodrigues. Comunidades Aprendentes. In: FERRARO JUNIOR, Luiz Antonio. Encontros e caminhos: formação de educadoras(es) ambientais e coletivos educadores. Brasília: MMA. Diretoria de Educação Ambiental, 2005, p. 83-92.

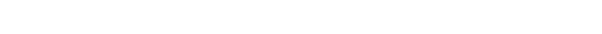


CARVALHO, Isabel Cristina de Moura. Educação ambiental: a formação do sujeito ecológico. São Paulo: Cortez, 2008.

CRUZ, Pedro José Santos Carneiro. Extensão popular: situando a extensão universitária orientada pela educação popular. In: CRUZ, Pedro José Santos Carneiro, et al. Extensão popular: caminhos em construção. João Pessoa-PB: Editora CCTA, 2017.

DUSSEL, Enrique Domingos. Cultura latino-americana e filosofia da libertação (cultura popular revolucionária, além do populismo e do dogmatismo). In: DUSSEL, Enrique Domingos. Oito ensaios sobre cultura latino-americana e libertação. São Paulo: Paulinas, 1997, p. 171-231.

EDUARDA. Registro em diário de campo. Uberaba (Minas Gerais), 30 jan. 2017.

FLICK, Uwe. Introdução à pesquisa qualitativa. 3. ed. Tradução de Joice Elias Costa. São Paulo: Artmed, 2009. (Obra original publicada em 1995).

FREIRE, Paulo. Extensão ou comunicação? 17.ed. São Paulo: Paz e Terra, 2015.

FREIRE, Paulo. Educação e mudança. 34.ed. Rio de Janeiro: Paz e Terra, 2011a.

FREIRE, Paulo. Educação como prática da liberdade. 34.ed. Rio de Janeiro: Paz e Terra, 2011b.

FREIRE, Paulo. Ação cultural para a liberdade. 13.ed. Petrópolis RJ: Paz e Terra, 2007.

FREIRE, Paulo. Pedagogia da esperança: um reencontro com a pedagogia do oprimido. Rio de Janeiro: Paz e Terra, 2008.

FREIRE, Paulo. Pedagogia do oprimido. São Paulo: Editora UNESP, 2005.

FREIRE, Paulo. Professora sim, tia não - cartas a quem ousa ensinar. São Paulo: Olho d'água, 1999.

FREIRE, Paulo. Pedagogia da autonomia: saberes necessários à prática educativa. 7.ed. Rio de Janeiro: Paz e Terra, 1996.

JOÃO. Registro em diário de campo. Uberaba (Minas Gerais), 30 jan. 2017.

LARROSA-BONDÍA, Jorge. Notas sobre a experiência e o saber da experiência. In. Revista Brasileira de Educação, jan./fev./mar./abr., n. 19, 2002.

LÚCIA. Registro em diário de campo. Uberaba (Minas Gerais), 30 jan. 2017.

MARCONI, Marina de Andrade; LAKATOS, Eva Maria. Técnicas de Pesquisa: planejamento e execução de pesquisas, amostragens e técnicas de pesquisas, elaboração, análise e interpretação de dados. 5.ed. São Paulo: Atlas, 2002.

MÔNICA. Registro em diário de campo. Uberaba (Minas Gerais), 30 jan. 2017.

OLIVEIRA, Maria Waldenez de. Pesquisa e trabalho profissional como espaços e processos de humanização e de comunhão criadora. Cad. Cedes, Campinas, vol. 29, n. 79, p. 309-321, set./dez. 2009.

OLIVEIRA, Maria Waldenez de; RIBEIRO JUNIOR, Dijalma; SILVA, Douglas Verrangia Corrêa da; SOUSA, Fabiana Rodrigues de; VASCONCELOS, Valéria Oliveira de. Pesquisando processos educativos em práticas sociais. In: OLIVEIRA, Maria Waldenez de; SOUSA, Fabiana Rodrigues de. (org.). Processos educativos em práticas sociais: pesquisas em educação. São Carlos: EdUFSCar, 2014, p. 113-141.

OLIVEIRA, Maria Waldenez; STOTZ, Eduardo Navarro. Perspectivas de diálogo no encontro entre organizações governamentais e instituição acadêmica: o convívio metodológico. In: REUNIÃO ANUAL DA ANPEd, 27., 2004, Caxambú. Anais: "Sociedade, democracia e educação: qual Universidade?" Caxambú: ANPEd, 2004.

PEDRO. Registro em diário de campo. Uberaba (Minas Gerais), 30 jan. 2017. 
ROSA, Isaquiel Macedo da. Educação popular, integralidade e formação em enfermagem no cenário da extensão universitária. (Universidade Federal do Rio Grande do Sul) 2011. 119f. Dissertação. (Mestrado em Enfermagem). Programa de Pós-graduação em Enfermagem, Universidade Federal do Rio Grande do Sul, Porto Alegre, 2011.

SARA. Registro em diário de campo. Uberaba (Minas Gerais), 30 jan. 2017.

SAUVÉ, Lucie. Educação Ambiental: possibilidades e limitações. Educação e pesquisa, São Paulo, v. 31, n. 2, p. 317-322, maio/ago. 2005.

SILVA, Petronilha Beatriz Gonçalves. Educação e identidade dos negros trabalhadores rurais do limoeiro. 1987, 293f. (Tese de Doutorado) - Programa de Pós-Graduação em Educação, Universidade Federal do Rio Grande do Sul, 1987.

SILVA, Petronilha Beatriz Gonçalves; ARAUJO-OLIVERA, Sonia Stella. Cidadania, ética e diversidade: desafios para a formação em pesquisa. VI Encuentro - Corredor de las ideas del cono sur "Sociedad civil, democracia e integración" - Montevideo - 12 marzo 2004. Salón 3 - Educación Educación Superior.

SOUZA, Tiago Zanquêta de. A extensão popular e a produção do conhecimento conversitário. Cad. Pesq., São Luís, v. 26, n. 2, p. 237-256, abr./jun., 2019.

TEIXEIRA, Iraí Maria Campos; RIBEIRO JUNIOR, Djalma; SOUZA, Erivelto Santiago; OLIVEIRA, Maria Waldenez de; COSTA, Reijane Salazar; SOUZA, Rosângela Pereira de; ALMEIDA, Sara Ferreira de; BOGADO, Adriana; SOUSA, Fabiana Rodrigues de; FIDÉLIX, Ana Paula; SOUZA, Tiago Zanquêta de. Texto de estudos - cosmovisão (acompanha seção de debates sobre convivência). Grupo de Pesquisa Práticas Sociais e Processos Educativos, UFSCar/São Carlos/SP, 2015.

VALLA, Victor Vincent. A crise de interpretação é nossa: procurando compreender a fala das classes subalternas. Educação \& Realidade. Jul./dez. 1996.

VERGARA, Sylvia Constant. Métodos de coleta de dados no campo. São Paulo: Atlas, 2009.

Submetido em agosto de 2020

Aprovado em fevereiro de 2022

\section{Informações do(a)(s) autor(a)(es)}

Tiago Zanquêta de Souza

Programa de Pós-Graduação em Educação (mestrado e doutorado) e Programa de Pós-Graduação em Educação: formação docente para a Educação Básica, ambos da Universidade de Uberaba (Uniube), Uberaba/MG, Brasil. Líder do Grupo de Pesquisa em Formação Docente, Direito de Aprender e Práticas Pedagógicas (CNPq/Uniube). Membro do Grupo de Pesquisa em Práticas Sociais e Processos Educativos (CNPq/UFSCar).

E-mail:tiago.zanqueta@uniube.br

ORCID: https://orcid.org/0000-0002-2690-4177

Link Lattes: http://lattes.cnpq.br/2263664575012618

Maria Waldenez de Oliveira

Programa de Pós-Graduação em Educação - Universidade Federal de São Carlos (UFSCar). Líder do

Grupo de Pesquisa em Práticas Sociais e Processos Educativos (CNPq/UFSCar). 
E-mail:dmwo@ufscar.br

ORCID: https://orcid.org/0000-0001-6362-8581

Link Lattes: http://lattes.cnpq.br/3404769527869004 